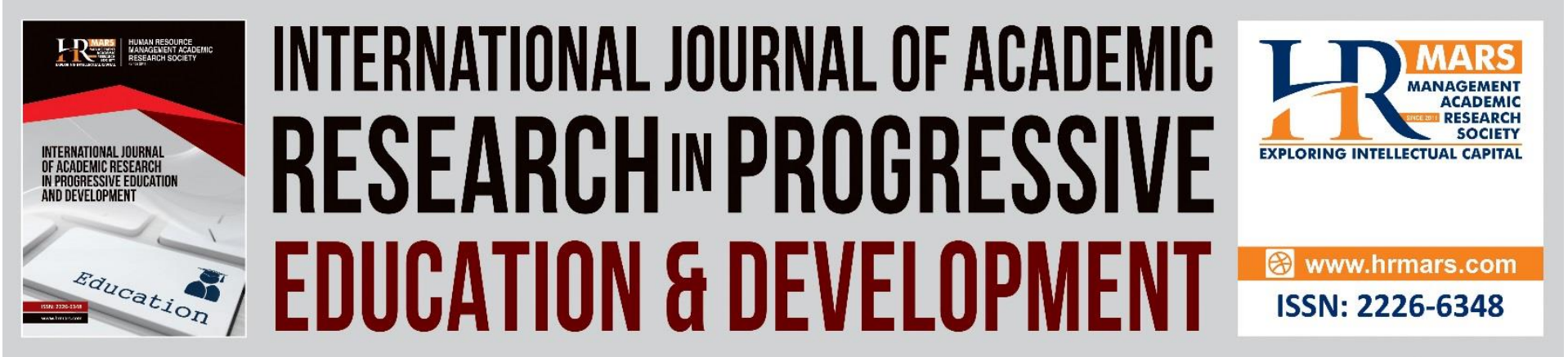

\title{
L1 vs L2 Preferences in Malaysian ESL Classrooms
}

\author{
Siti Nur Yusof, Siti Nur Laily Hussin, Farzaana Abdul Kadir
}

To Link this Article: http://dx.doi.org/10.6007/IJARPED/v10-i3/11014

DOI:10.6007/IJARPED/v10-i3/11014

Received: 08 July 2021, Revised: 29 July 2021, Accepted: 19 August 2021

Published Online: 22 September 2021

In-Text Citation: (Yusof et al., 2021)

To Cite this Article: Yusof, S. N., Hussin, S. N. L., \& Kadir, F. A. (2021). L1 vs L2 Preferences in Malaysian ESL Classrooms. International Journal of Academic Research in Progressive Education and Development, 10(3), $1196-1210$.

Copyright: (C) 2021 The Author(s)

Published by Human Resource Management Academic Research Society (www.hrmars.com)

This article is published under the Creative Commons Attribution (CC BY 4.0) license. Anyone may reproduce, distribute, translate and create derivative works of this article (for both commercial and non-commercial purposes), subject to full attribution to the original publication and authors. The full terms of this license may be seen at: http://creativecommons.org/licences/by/4.0/legalcode

Vol. 10(3) 2021, Pg. $1196-1210$

http://hrmars.com/index.php/pages/detail/IJARPED

JOURNAL HOMEPAGE

Full Terms \& Conditions of access and use can be found at http://hrmars.com/index.php/pages/detail/publication-ethics 


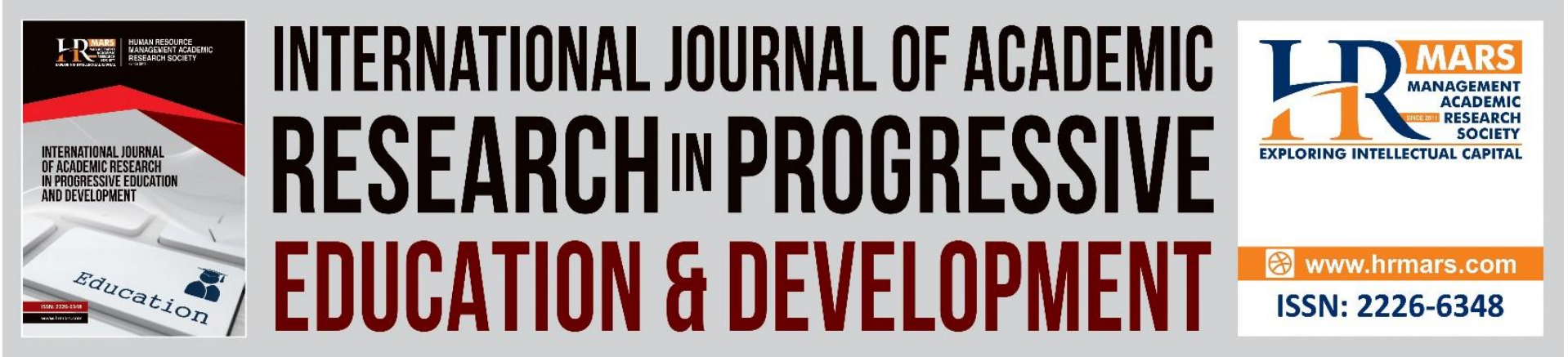

\title{
L1 vs L2 Preferences in Malaysian ESL Classrooms
}

\author{
Siti Nur Yusofa, Siti Nur Laily Hussin ${ }^{\mathrm{b}}$, Farzaana Abdul Kadir ${ }^{\mathrm{b}}$ \\ ${ }^{a}$ Faculty of Languages and Communication, Universiti Pendidikan Sultan Idris, ${ }^{b}$ Faculty of \\ Education, Universiti Kebangsaan Malaysia
}

\begin{abstract}
Being bilingual or multilingual is a huge advantage. However, when it comes to learning the second language (L2), the first language (L1) tends to be seen as either facilitator or barrier. This is totally depending on how L1 is being utilised mainly in language classrooms. This study aims to identify the patterns of students' preferences in using L1 and L2 when interacting with their ESL teachers and peers; and doing work in groups or pairs and as whole class in ESL classrooms at National Secondary School (SMK) and National Type (Chinese) Secondary School (SMJKC) in Malaysia. The findings revealed that majority of the students prefer to use L2 when they interact with their teacher and when having whole class discussion;and L1 when they interact with peers and working in groups or pairs. This decreases students'chance to practice L2 (English language). Thus, study highlighted that there is a need to maximise practice of using L2 in language classrooms as students tend not to practice outsidethe classroom and even when doing some activities in the classroom.
\end{abstract}

Keywords: First Language (L1), Second Language (L2), Preferences, ESL Classrooms

\section{Introduction}

"If you talk to a man in the language he understands, that goes to his head. If you talkto a man in his language, that goes to his heart" by Nelson Mandela.

Being a multicultural country, Malaysia has many different ethnics, religions and languages spoken by its people. To promote unity, Bahasa Malaysia is placed as the nationallanguage where in education system of Malaysia, it is taught as a subject which students fromall background must learn to be able to interact with different ethnicity (Yusof, 2012). On the other hand, English is position as the second language in Malaysia and is often used by peopleof different cultural background to communicate besides Bahasa Malaysia. Most Malaysians are therefore are either bilingual or multilingual as they learn both Bahasa Malaysia and English in addition to their mother tongue language (L1). When to use which language goes back to their own preferences depending on context, situation and people they are talking to.

In terms of education, besides having national schools (Malay as medium) there are also national type schools where Chinese or Tamil is used as medium of instruction (Wen and Chibundu, 2018). Bahasa Malaysia is the official language and mother tongue for most Malays 
in Malaysia, while English is positioned as the second language in the Malaysian education system (Darmi et. al., 2018). Be it in national type schools or national schools, both Bahasa Malaysia and English are taught in addition to L1 (in national type schools). Research has frequently proven that first (L1) and second (L2) languages play different roles in language classroom (Chavez, 2003).

It is not possible to refrain students from using L1 when they are in ESL classroom. So,L1 should be used as a plus point to enhance students learning in L2 classroom. Identifying students' patterns of preference on using either L1 or L2 when doing different tasks and whenspeaking with others may lead teachers to be able to design suitable activities and surrounding. By this, teachers could then ensure that students utilise L1 when L1 acts as a facilitator and not as barrier for L2 learning. In this study, researchers seek to describe the patterns of students' preferences in using L1 and L2 based on whom they are interacting with(ESL teachers or peers) and during activities (groups/pairs or whole class) in ESL classroomsat National Secondary School (SMK) and National Type (Chinese) Secondary School (SMJKC) in Malaysia.

\section{Problem Statement}

Usage of $\mathrm{L} 1$ has been an often talk about topic in the field of English language teaching(Darmi et. al., 2018). Many researchers and practitioners believe that L1 should not be used at all in L2 classroom because it may lead to less effective pedagogical practice (Chavez, 2003). Although using L1 in English as Second Language (ESL) classroom is seen as a barrierfor students' L2 development but there are researchers who highlighted the plus points of $L 1$ in $L 2$ learning process (Darmi et. al., 2018). However, it is undeniable that L1 has roles to playin L2 classroom as it may fill in the gaps for students to learn better indirectly.

Using L1 or L2 when being in ESL classroom depends on the preferences and beliefs of the teachers when teaching with references to their experience and knowledge. Nonetheless for students, they tend to use the language which help them to communicate their message and succeed in their goal (of a task) best even when they are in the ESL classroom (Chavez, 2003; Carless, 2008). Besides, students tend to use L1 when they are around peers whom they share similar L1 or national language with (Notion, 2003; cited in Darmi et. al., 2018). This shows that students choose to use L1 depending on situations (tasksthey are doing) and people they are speaking to. Most of the studies on language preferencesare done on teachers (Darmi et al., 2018; Yussof \& Sun, 2020) and apart from that there are very limited studies on this issue in Malaysia (Jumal, AlSaqqaf \& Nik, 2019). Among popular studies in Malaysia regarding students are usually on reasons for code-mixing (e.g. Jumal et. al., 2019) and how L1 may interfere with certain English language elements (e.g. Arumugam et. al., 2017; Krish \& May, 2020). Thus, in this study, researchers aim to identify the languagepreferences of ESL students at schools in Malaysia.

\section{Research Question}

What are the language preferences of students in ESL classroom at National Secondary School (SMK) and National Type (Chinese) Secondary School (SMJKC) in Malaysia:
a) when interacting with ESL teachers?
b) when interacting with peers?
c) when working in pairs or groups?
d) when working as a whole class? 


\section{Literature Review}

\section{Diglossia in Malaysian Schools}

Although initially defined as language situation where there is high and low variety of thesame language, diglossia's definition was later extended by Fishman (1967) as he stated thatthe high and low varieties not necessarily need to be of same language (Muller and Ball, 2005).Chavez (2003) stated that "although learners are usually not full-fledged bilinguals, they do have two languages at their disposal, at least in some context, for different purposes, and to varying degrees of sophistication" (pg. 163). This situation then creates opportunity for diglossia. Besides, Chavez (2003) defines code-switching as part of diglossia. Code-switchingis when two languages of two varieties of a language are used in the same speech circumstance (Muller \& Ball, 2005).

In Malaysia, Platt (1977) describes existence of polyglossia as he added moderate prestige level for languages such as colloquial Malaysian English and regional varieties of Chinese (Muller and Ball, 2005). This is due to a lot of interaction of high prestige languages (Bahasa Indonesia - now known as Bahasa Malaysia in Malaysia; and formal Malaysian English) and for instance Chinese languages which are non-dominant, low variety. Being a multicultural multilingual country, Bahasa Malaysia is frequently used by Malaysian students to communicate with different ethnics in their classrooms and during co-curriculum activities (Yusof, 2012). In a diglossic classroom, both teachers and students have their preferences based on rules that they have internalised personally when it comes to choosing either to use L1 or L2 (Chavez, 2003).

When learners' L1s are similar and they have limited metacognitive skills of L2, L1 becomes critical. The use of $\mathrm{L} 1$ will assist students in reflecting on language and guiding themthrough the tasks (Darmi et. al., 2018). Sert (2005) highlighted four main functions of students' codeswitching which are equivalence (using L1 due to limited L2 vocabulary), floor holding (using L1 to communicate effectively when they know the mean of the L2 word but not able to recall the word), reiteration (repeating terms spoken in L2 into L1 thinking that they are not communicating clearly) and conflict control (using L1 to avoid misinterpretation of message in L2). Even though there are evidence of the roles of code-switching or diglossia in language classroom, the professionals have yet to agree whether it is a benefit or hindrance to $L 2$ learning (Chavez, 2003).

\section{Exposure to English language among Malays and Chinese Malaysians in Education}

During the British collonisation in Malaysia, the Indian and Chinese were given rights toget English education but not the Malays (Vollmann and Soon, 2018). The Malays were less likely to be exposed to English language except if they were from the elites. Wahid and Pilus (2017) in their study investigating the 'third space', as they term it, a specific context in whichstudents learn English formally, revealed that Malay community is reluctant to utilise English due to interference of identity, religion and first language. This causes an issue for those students who are willing to speak in English in their community by not having people to speakto which causes their motivation to decline. Wahid and Pilus (2017) highlighted that English- medium university which consists of people sharing the same L1 is not a successful 'third space' as some students, depending on context would prefer using Malay language instead of English. Therefore, they suggested that classroom or task-based activities outside the classroom are likely to be more suitable third space for Malay students to practise English. 
There was segregation among Chinese Malaysians in the past where they joined eitherEnglish or Chinese medium education but now, they received trilingual education (Mandarin,Malay and English) (Carstens, 2018). Chinese Malaysian families tend to expose their childrento either Mandarin or English as their L1 but Mandarin is more common. Before 1970s, Chinese parents chose to send their children to English schools as English education was anoption in national schools in Malaysia and when English medium was not an option, Chinesestudents were sent to Mandarin medium schools (Carstens, 2018). Chinese Malaysian students are mostly exposed to their L1 when they are in Mandarin medium schools as they are surrounded by people of the same background. However, it is evident that Chinese Malaysians give importance to English language education. Currently, both Chinese and Malay students are now learning English as a subject at any government schools. The only distinction is SMK students are exposed to Malay as medium of instruction in both primary and secondary schools while SMJKC students have the luxury of having Mandarin-medium primary education before adapting to Malay as the medium of instruction at secondary level.

Carstens (2018) in her study found that Chinese students tend to use English when theyare communicating with friends from different ethnics while they use more Mandarin when they speak with Chinese speakers in public. When it comes to writing (such as on social media), students choose English as they find it easier. Carstens (2018) stated that although English education may help students' chances for professional advancement, learning Mandarin is vital for the Chinese community to sustain their identity. Today, Chinese Malaysians believe Chinese and English are both crucial languages for discourse among themselves and also internationally. Thus, parents who could afford international schools would send their children there for education as they would be able to learn and practice English better.

\section{ESL in Malaysian Classrooms}

Darmi et. al. (2018) stated that Malaysian teachers have a common belief when it comesto English language teaching and learning which is they are only using English in the classroom. On the other hand, according to Richard and Rodgers (2001) the Grammar Translation method, in which learners utilised both L1 and L2, translating to and from L1 to learn L2 for better understanding of the meaning are still utilised as the main teaching methodin Asia's language classrooms (as cited in Darmi et. al., 2018). Therefore, it is proven that to teach L2 using L1 is an established method of teaching L2 because when using Grammar Translation method, L1 plays a huge part in learning L2.

However, in Malaysia initially, Communicative Language Approach was implemented for English language learning in Malaysia where there were two main streams, Task-Based Syllabuses (language use practice in real situations) and Notional Syllabuses (emphases on meanings) (Darmi et. al., 2018). Now, implemented under the blueprint "English Language Education Reform in Malaysian: The Roadmap 2015-2025" by the Ministry of Education (MOE) Malaysia, the Common European Framework of Reference for Languages (CEFR) is used for English language education in Malaysia (Darmi et. al., 2018). This action is taken in the hope of enhancing the English language skills among Malaysian students.

\section{Use of L1 in Language Classes}

L1 is not necessarily a barrier to learning L2 but as language serves different functions for instance in classroom, different or mixture of languages may be utilised to give instructions, 
feedbacks and when practicing maximizing comprehension (Chavez, 2003). Instead, not allowing students to use L1 among themselves may act as barrier for them to share their thoughts due to having inadequate L2 vocabulary (Darmi et. al., 2018). Nation (2003) found that when all students in a classroom share the same national language or L1, there is a possibility that they work on tasks using $L 1$ as that is more convenient for them to communicate effectively (cited in Darmi et. al., 2018). Besides facilitating students' language learning, L1 gives opportunity to students to succeed in their group and pair work without always using only L2 (Carless, 2008).

Studies (Hancock, 1997; Anton and DiCamilla, 1998) have proven that students tend touse L1 when they talk to themselves (self-talk) and when they support one another while working on a task. Additionally, these studies highlighted that $\mathrm{L} 1$ is crucial when giving instructions, asking questions and in problem solving tasks as it serves as a tool to scaffold students learning (Chavez, 2003). Schemata of the student with low L2 proficiency needs to be activated for them to succeed in language learning (Darmi et. al., 2018). Therefore, using L1 in classroom works as scaffolding when doing activities in $L 2$ as it helps students to solve problems and understand tasks (Liao, 2006 as cited in Darmi et. al., 2018).

According to Chavez (2003) students readily use L2 when it comes to practising the language (pedagogical function) while they use L1 for real communication such as explanations (real functions). Here, L1 plays an important role and serves as a vehicle of "real" communication. Besides, Chavez (2003) zoomed in some studies (Platt and Brooks, 1994; Blyth, 1995; Lin, 1999) which revealed that teachers who use L1 in their classrooms help to lessen students' anxiety and create better rapport with the learners. Students' confidence levelmay increase and they may practice in L2 more when teachers ensure a safe and positive classroom.

\section{Methodology}

In this current study, a quantitative approach was used to examine the use of L1 and L2 in ELS contexts of Malaysian national secondary schools (SMK) and Chinese national typeschools (SMJKC).

\section{Research Design}

In order to identify patterns among our samples either in their opinions, attitudes, behaviours or features (Creswell, 2012), a survey design was chosen as the research designof this current study. The questionnaire by Chavez (2003) on students' preference between L1 and L2 (German) among 3 different levels of university students was adapted to be used as the online survey questionnaire.

Instrumentation

This survey consisted 43 questions which were parts of Chavez's (2003) 158 questions. For this mini research, only questions that required students to self-report on their language use based on each described situation were used. We did not take the other questions which dealt with teachers' desired and observed language use as well as students'desired language use. The online version of the survey was made available as the tool for this study data collection. The questionnaire was divided into two parts, namely the demographic of the respondents and the 43 questions. The former part was specifically meant to select respondents who matched the purposive sampling criteria. Instead of using 5 Likert-scale likeChavez did, we only gave either L1 or L2 as answer options. This was the only adapted part that was done to the 
questionnaire. The respondents were asked to evaluate themselves usingthis instrument and reflected on which language that used for described situations.

Sampling Technique \& Respondents

All the respondents of this survey are 16 years old. Thus, they possessed the same number of years of formal exposure to ESL as a subject at schools. The respondents from SMK must have Bahasa Malaysia as their first language and their SMJKC counterparts shouldhave Mandarin as their mother tongue. To ensure the sample possessed the said characteristics, purposive sampling was used. A link to the online survey was shared to threeESL teachers of SMK and three ESL teachers of SMJKC in Klang Valley. The respondents were all Science streams students so that we could assume that they shared similar level of academic performance.

Data Collection \& Analysis

The data for this study was collected from form 4 science stream students of 3 differentSMK schools and 3 SMJKC schools in Klang Valley through an online survey link. A total of 132 responses were recorded but only 40 SMK and 40 SMJCK students were selected as deemed suitable following the characteristics set for the sample. Before using descriptive statistical analysis to analyse the data, the percentages and frequency of the responses wereobtained from the instrument administered.

Findings

The findings of this analysis are summarised in four tables which directly answer allfour subresearch questions (RQ1a, RQ1b, RQ1c, RQ1d). Next, the interpretation of the data will be done in the discussion section.

RQ1a: What are the language preferences of students in ESL classroom at national secondary school (SMK) and Chinese national type secondary school in Malaysia when interacting with ESL teachers? Table 1: Students' Language Preferences when Attempting Tasks Involving Interaction with Teachers 


\begin{tabular}{|c|c|c|c|c|c|}
\hline NO & ITEMS & SMK S & TUDEN & $\begin{array}{l}\text { SSMJKC } \\
\text { STUDE }\end{array}$ & \\
\hline & Which language do I use when .... ? & $\mathrm{L} 1(\mathrm{n})$ & $\mathrm{L} 2(\mathrm{n})$ & $\mathrm{L} 1(\mathrm{n})$ & L2(n) \\
\hline & & $\%$ & $\%$ & $\%$ & $\%$ \\
\hline 1 & I ask the teacher questions about a new grammar point & 24 & 16 & 37 & 3 \\
\hline & & $\underline{60}$ & 40 & $\underline{92.5}$ & 7.5 \\
\hline 2 & I ask the teacher questions in a grammar review & 24 & 16 & 38 & 2 \\
\hline & & $\underline{60}$ & 40 & $\underline{95}$ & 5 \\
\hline 5 & I ask the teacher questions about new vocabulary & 30 & 10 & 35 & 5 \\
\hline & & $\underline{75}$ & 25 & $\underline{87.5}$ & 12.5 \\
\hline 6 & I ask the questions in a vocabulary review & 26 & 14 & $\overline{34}$ & 6 \\
\hline & & $\underline{65}$ & 35 & $\underline{85}$ & 15 \\
\hline 9 & I ask the teacher as s/he explains about the background & 29 & 11 & 37 & 3 \\
\hline & fora reading text & $\underline{72.5}$ & 27.5 & $\underline{92.5}$ & 7.5 \\
\hline 10 & I ask the teacher as s/he explains about the background & $\overline{22}$ & 18 & 37 & 3 \\
\hline & foran audio or video tape & $\underline{55}$ & 45 & $\underline{92.5}$ & 7.5 \\
\hline 11 & I ask the teacher about general cultural issues & $\overline{15}$ & 25 & 36 & 4 \\
\hline & & 37.5 & $\underline{62.5}$ & $\underline{90}$ & 10 \\
\hline 12 & I ask the teacher about instructions on a homework & 22 & 18 & 38 & 2 \\
\hline & assignment & $\underline{55}$ & 45 & $\underline{95}$ & 5 \\
\hline 13 & I ask the teacher about instructions on a test & 21 & 19 & $\overline{37}$ & 3 \\
\hline & & $\underline{52.5}$ & 47.5 & $\underline{92.5}$ & 7.5 \\
\hline 14 & I ask the teacher about the syllabus or course & $\overline{16}$ & 24 & $\overline{36}$ & 4 \\
\hline & & 40 & $\underline{60}$ & $\underline{90}$ & 10 \\
\hline 15 & I ask the teacher about instructions for group or pair & 24 & 16 & 34 & 6 \\
\hline & work & $\underline{60}$ & 40 & $\underline{85}$ & 15 \\
\hline 17 & I ask the teacher about how to express something with & 24 & 16 & 34 & 6 \\
\hline & good grammar & $\underline{60}$ & 40 & 85 & 15 \\
\hline 18 & I ask the teacher about which word to use & $\overline{24}$ & 16 & 35 & 5 \\
\hline & & $\underline{60}$ & 40 & $\underline{87.5}$ & 12.5 \\
\hline 27 & the teacher checks how well students comprehended a & 29 & 11 & 36 & 4 \\
\hline & reading & $\underline{72.5}$ & 27.5 & $\underline{90}$ & 10 \\
\hline 28 & the teacher checks how well students comprehended an & $\overline{24}$ & 16 & $\overline{37}$ & 3 \\
\hline & audio or video tape & $\underline{60}$ & 40 & $\underline{92.5}$ & 7.5 \\
\hline 32 & I make small talk with the teacher (in class) & $\overline{23}$ & 17 & 34 & 6 \\
\hline & & $\underline{\underline{57.5}}$ & 42.5 & $\underline{85}$ & 15 \\
\hline 34 & I joke with the teacher (in class) & $\overline{6}$ & 34 & 33 & 7 \\
\hline & & 15 & $\underline{85}$ & $\underline{82.5}$ & 17.5 \\
\hline 40 & I perform routines, such as greeting the teacher \& other & 16 & $\overline{24}$ & $\overline{31}$ & 9 \\
\hline & students, asking which page the class is on, etc. & 40 & $\underline{60}$ & $\underline{77.5}$ & 22.5 \\
\hline 41 & I visit the teacher's office hours & 13 & $\overline{27}$ & $\overline{33}$ & 7 \\
\hline & & 32.5 & $\underline{67.5}$ & $\underline{82.5}$ & 17.5 \\
\hline 42 & I run into the teacher outside of class, by chance & 18 & 22 & 30 & 10 \\
\hline & & 45 & $\underline{\underline{55}}$ & $\underline{75}$ & 25 \\
\hline
\end{tabular}


Based on Table 1, we can observe that there are 20 items covering the situationswhere students have to interact with ESL teachers either in classroom setting or outside classroom setting. The situations described also cover instructional and social settings. It is reported that all SMK students preferred to use L2 (English) when interacting with ESL teachers except for 6 situations (items 11, 14, 34, 40, $41 \& 42$ ). Those six items are about joking with teachers, interacting with teachers outside classroom and talking about new topicsor topics which are not related to the particular discussed subject matter during that instructional time. On the other hand, all SMJKC students chose to use English while interacting with their ESL teachers in all settings and situations. The percentage is more conclusive as the lowest percentage is $75 \%$ and highest is $95 \%$ compared to the percentageof SMK students which only varies from 52.5 to $72.5 \%$ only.

RQ1b: What are the language preferences of students in ESL classroom at national secondary school (SMK) and Chinese national type secondary school (SMJKC) in Malaysia when interacting with peers?

Table 2: Students' Language Preferences when Attempting Tasks Involving Interaction with Peers

\begin{tabular}{|c|c|c|c|c|c|}
\hline \multirow[t]{3}{*}{ NO } & \multirow{3}{*}{$\begin{array}{l}\text { ITEMS } \\
\text { Which language do I use when ....? }\end{array}$} & \multicolumn{4}{|c|}{$\begin{array}{l}\text { SMK STUDENTS SMJKC } \\
\text { STUDENTS }\end{array}$} \\
\hline & & L1(n) & $\mathrm{L} 2(\mathrm{n})$ & $\mathrm{L} 1(\mathrm{n})$ & L2(n) \\
\hline & & $\%$ & $\%$ & $\%$ & $\%$ \\
\hline \multirow[t]{2}{*}{19} & I ask other students about how to express something & 7 & 33 & 10 & 30 \\
\hline & withgood grammar & 17.5 & $\underline{82.5}$ & 25 & $\underline{75}$ \\
\hline \multirow[t]{2}{*}{20} & I ask other students about which word to use & 5 & $\overline{35}$ & 8 & $\overline{32}$ \\
\hline & & 12.5 & $\underline{87.5}$ & 20 & $\underline{80}$ \\
\hline \multirow[t]{2}{*}{26} & I review other students' work & 10 & $\overline{30}$ & 9 & 31 \\
\hline & & 25 & $\underline{75}$ & 22.5 & $\underline{77.5}$ \\
\hline \multirow[t]{2}{*}{33} & I make small talk with other students (in class) & 3 & $\overline{37}$ & 6 & $\overline{34}$ \\
\hline & & 7.5 & $\underline{92.5}$ & 15 & $\underline{85}$ \\
\hline \multirow[t]{2}{*}{35} & I joke with other students (in class) & 2 & $\overline{38}$ & 4 & 36 \\
\hline & & 5 & $\underline{95}$ & 10 & $\underline{90}$ \\
\hline \multirow[t]{2}{*}{36} & I give written feedback on my classmates' written work & 6 & $\overline{34}$ & 21 & $\overline{19}$ \\
\hline & & 15 & $\underline{85}$ & $\underline{52.5}$ & 47.5 \\
\hline \multirow[t]{2}{*}{37} & I give oral feedback on my classmates' written work & 8 & 32 & $\overline{18}$ & 22 \\
\hline & & 20 & $\underline{80}$ & 45 & $\underline{55}$ \\
\hline \multirow[t]{2}{*}{38} & I give written feedback on my classmates' speaking & 14 & 26 & 19 & $\overline{21}$ \\
\hline & performance & 35 & $\underline{65}$ & 47.5 & $\underline{52.5}$ \\
\hline \multirow[t]{2}{*}{39} & I give oral feedback on my classmates' speaking & 13 & $\overline{27}$ & 15 & $\overline{25}$ \\
\hline & performance & 32.5 & $\underline{67.5}$ & 37.5 & $\underline{62.5}$ \\
\hline \multirow[t]{2}{*}{43} & I run into other students outside of class & 5 & $\overline{35}$ & 9 & 31 \\
\hline & & 12.5 & 87.5 & 22.5 & 77.5 \\
\hline
\end{tabular}

Table 2 contains 10 items that show the interaction between peers who are not tied tothe classroom setting. This goes beyond the ESL classroom, although some of the situationsdeal with the ESL subjects. SMK students preferred to use L1 (Malay) when speaking to theirpeers in all situations and environments. The percentage is between $65 \%$ and $95 \%$. Similarly, 
SMJKC students also chose to use L1 (Mandarin) when interacting with their classmates, with the exception of item 36. Even so, the preference for this particular situation (written feedback on classmates' written work) is not so conclusive, since the difference is only 1 person between L1 and L2 preferences. This is an interesting finding that will be discussed further in the discussion section.

RQ1c: What are the language preferences of students in ESL classroom at national secondary school (SMK) and Chinese national type secondary school in Malaysia when working in pairs or groups?

Table 3: Students' Language Preferences when Attempting Tasks Done in Pairs or Groups

\begin{tabular}{|c|c|c|c|c|c|}
\hline NO & ITEMS & SMK S & UDENTS & $\begin{array}{l}\text { SMJK } \\
\text { STUDE }\end{array}$ & \\
\hline & Which language do I use when .... ? & $\mathrm{L} 1(\mathrm{n})$ & $\mathrm{L} 2(\mathrm{n})$ & $\mathrm{L} 1(\mathrm{n})$ & L2(n) \\
\hline & & $\%$ & $\%$ & $\%$ & $\%$ \\
\hline 4 & I practice grammar with other students in group or pai & & 33 & 12 & 28 \\
\hline & work & 17.5 & $\underline{82.5}$ & 30 & $\underline{70}$ \\
\hline 8 & I practice vocabulary with other students in group or & 11 & 29 & 12 & 28 \\
\hline & pairwork & 27.5 & $\underline{72.5}$ & 30 & $\underline{70}$ \\
\hline 16 & I discuss instructions for group or pair work with other & 3 & 37 & 6 & 34 \\
\hline & students & 7.5 & $\underline{92.5}$ & 15 & $\underline{85}$ \\
\hline 21 & I make small talk with other students (in class) & 13 & 27 & 18 & 22 \\
\hline & & 32.5 & $\underline{67.5}$ & 45 & $\underline{55}$ \\
\hline 22 & I practice vocabulary in groups or pairs & 16 & 24 & 17 & 23 \\
\hline & & 40 & $\underline{60}$ & 42.5 & $\underline{57.5}$ \\
\hline 23 & I discuss issues in groups or pairs & 2 & 38 & 11 & 29 \\
\hline & & 5 & $\underline{95}$ & 27.5 & $\underline{72.5}$ \\
\hline 24 & I use when I engage in role play with other students & 13 & $\overline{27}$ & 22 & $\overline{18}$ \\
\hline & & 32.5 & $\underline{67.5}$ & $\underline{55}$ & 45 \\
\hline 25 & I solve problems in groups or pairs & 3 & 37 & 9 & 31 \\
\hline & & 7.5 & $\underline{92.5}$ & 22.5 & $\underline{77.5}$ \\
\hline
\end{tabular}

There are 8 items in Table 3. The items represent the tasks in ESL classrooms in whichstudents are required to work in pairs and groups. The survey results show that L1 (Malay) ismore preferred by SMK students when talking to their pairs or group members in completing the tasks in a classroom setting. The finding is quite convincing as the average for the percentage of all items is $78.75 \%$. Mirroring the responses from SMK students, SMJKC students also chose to use L1 (Mandarin) while working in pairs or groups with the exceptionof item 24 . This item is about participating in role play activities and it is observed that only 22students advocated for L2 (English) as opposed to 18 students who utilised L1 (Mandarin) in performing this kind of activities. 
DEVELOPMENT

Vol. 10, No. 3, 2021, E-ISSN: 2226-6348 @ 2021 HRMARS

RQ1d: What are the language preferences of students in ESL classroom at national secondary school (SMK) and Chinese national type secondary school in Malaysia when working as a whole class?

Table 4: Students' Language Preferences when Attempting Tasks Done as a Whole Class

\begin{tabular}{|c|c|c|c|c|c|}
\hline NO & ITEMS & SMK S & IUDENT & $\begin{array}{l}\text { SSMJK } \\
\text { STUD }\end{array}$ & NTS \\
\hline & Which language do I use when ....? & $\mathrm{L} 1(\mathrm{n})$ & $\mathrm{L} 2(\mathrm{n})$ & L1(n) & L2(n) \\
\hline & & $\%$ & $\%$ & $\%$ & $\%$ \\
\hline 3 & the class practices grammar & 4 & 36 & 4 & 36 \\
\hline & & 10 & $\underline{90}$ & 10 & $\underline{90}$ \\
\hline 7 & the class practices vocabulary & 9 & $\overline{31}$ & 5 & $\overline{35}$ \\
\hline & & 22.5 & $\underline{77.5}$ & 12.5 & $\underline{87.5}$ \\
\hline 29 & the class discusses issues raised in a reading text & 14 & $\overline{26}$ & 6 & $\overline{34}$ \\
\hline & & 35 & $\underline{65}$ & 15 & $\underline{85}$ \\
\hline 30 & the class discusses issues raised in an audio or video & 18 & $\overline{22}$ & 7 & $\overline{33}$ \\
\hline & tape & 45 & $\underline{55}$ & 17.5 & $\underline{82.5}$ \\
\hline 31 & the class discusses with teacher (in class) how the & 8 & 32 & 3 & 37 \\
\hline & subjectis going & 20 & 80 & 7.5 & $\underline{92.5}$ \\
\hline
\end{tabular}

The 5 items on tasks done as a whole class are tabulated in Table 4 above. Overall, the SMK students' language preference is more inclined to L2 (English) use when working asa whole class. The percentage is between $55 \%$ and $90 \%$ whereas SMJKC students were moreinclined to use L2 (English) for this kind of activities with the average of $87.5 \%$ (82.5\% - 92.5\%)for all responses.

\section{Discussion}

From the analysed findings, there are four themes that could be discussed in this section, namely:

The language use pattern when interacting with ESL teachers

The language use pattern when interacting with peers

The language use pattern when working with pairs and group members

The language use pattern when working as a whole class during ESL lessons

The language use pattern when interacting with ESL teachers

From Table 1, it is observed that both SMK and SMJKC students generally preferred to use L2 (English) when they interact with their ESL teachers. SMJKC students used Englishwith their ESL teachers indiscriminately regardless of the situations and settings. However, SMK students did make distinction between formal/classroom setting and social/outside classroom setting. This is evident when SMK students preferred using L2 (English) in all 14 situations that required them to speak with their teachers while leaving the other 6 situations

with L1 (Malay) interaction. The latter situations take place during English lessons and outside classroom.

The first three situations where students asked ESL teachers questions about culturalissues (item 11), syllabus contents (item 14) and asking routine questions or even making routine greetings (item 40) are considered as social setting by SMK students even though those activities are done in the classroom setting. Here, we could clearly see that SMK students 
perceived anything that is not related to what is learnt during that particular lesson moves away from instructional setting. Perhaps Hancock's (1997 as cited in Chavez, 2003) description of how language learners sometimes subconsciously categorise the functions of language as they differentiate between "pedagogical" function being rehearsal functions suchas language practice and "real" function which serves true communication needs, really explained the logic behind SMK students' practice. It is proven that students tend to use L1 to avoid ambiguity in "real" function setting (Hancock as cited in Chavez, 2003).

The next situation described in item 34 is when students making jokes with teachers. This is clearly a social setting for which SMK students choose L1 for jokes or other attempts at relating to an interlocutor socially (Chavez, 2003). The other two items depict situations thattake place outside classrooms when students visit teacher's office (item 41 ) and accidentally run into ESL teachers out of class (item 42). This is in line with what Chavez (2003) shared inhis research that students tend to use L1 when they are not in classroom setting like during recess or whenever they exit from their classroom. What is striking similar among all these situations is SMK students perceived any interaction which is not directly related to the currentinstructional matter as social setting even though they are talking to ESL teachers. Arguably,SMK students are more prone to use L1 (Malay) as it is the dominant community speech in the schools and neighbouring area (Wahid \& Pilus, 2017).

After much analysis, it is noticed that SMJKC students are more consistent than SMKstudents (even with more conclusive percentages) in the language preference while interacting with ESL teachers as they remain to use English in classroom setting and pedagogical setting as well as outside classroom. This situation is perhaps similar to Chavez's (2003) research that shows Year 3 college students show more inclination to use German language in different settings and tasks as compared to their Year 2 and Year 1 College student counterparts. Since our respondents are all form 4 science stream students, their mastery and motivation to use L2 (English) might be more prominent than if they were Year 6students. Finally, the preconceived motivation that SMJKC students have since the British colonisation era that both their mother tongue and English are what matter for better life (Carstens, 2018) might contribute to the discrepancy between SMK and SMJKC students' percentage distributions.

The language use pattern when interacting with peers

SMK students preferred to use L1 when talking to their peers in all settings and situations. This result is replicated among SMJKC students in all items excluding one situationwhen they have to write feedback for their peers' essays (item 36). This odd result becomes more fascinating as only 2 people made the percentage incline to $L 2$ (English). After further analysis, it was found that the percentages for the other items that involved either giving writtenfeedback to peers' oral performance (items 38) and responding orally to peers' written work (item 37), were not that convincing compared to other tasks which provided clear difference in preference. These mixed responses when it comes to written tasks might be caused by the influence of L1 (Mandarin) writing drills. Menn, 2016 opines that the Chinese character writingdrills can either be transferred as a habitual L2 acquisition strategy or remained dominant strategy in L1 practice.

The discussion about all the other items for both SMK and SMJKC students even more interesting. The preference of mother tongue while talking to peers is taken as how L1 fullfils certain functions, and in this case is "real" function as opposed to pedagogical function which usually covers rehearsal function such as language practice (Chavez, 2003). Making jokes with 
friends serves as social function. Yusof (2012) highlighted that students in Vision School/Sekolah Wawasan, speak their own mother tongue with their peers. Research indicates that students generally use L1 when they want to fullfil genuinely communicative rather than pedagogical or practice function. Variables such as familiarity with the interlocutor or the strong desire to solve an intellectually challenging task (Chavez, 2003), just like giving feedbacks on peer's work in this questionnaire can compel students to use L1 to resolve local linguistic shortcomings.

The language use pattern when working with pairs and group members

Nation (2003) found that classmates who share the same national language or even L1, will prone to use that common shared language when they work in pairs or groups. They workon tasks using $\mathrm{L} 1$ as that is more convenient for them to communicate effectively. This notionis proven true in this research as all SMK and SMJKC students preferred using L1 when theyare asked to work in pairs or groups. Hancock (1997 as cited in Chavez, 2003) theorised aboutselftalk and meta-talk in which language learners tend to use L1 when thinking in monologuesand when defining situations or talking about instructions, procedures, or negotiation if turns which are all typical affairs in completing pair and group tasks. This finding is further supported by Darmi et al. (2018) when they found that the common shared language among students (L1) was used in group work to accommodate limited L2 metacognitive skills. The use of L1 will assist students in reflecting on language and guiding them through the tasks.

In contrast, in finding 3, there is one situation where SMJKC students would rather useL2 (English) than L1. It is when they are engaged in role play. Perhaps because the role playusually mimics the dialogue from $L 2$, it is natural for the activity to be done in L2. Unlike in finding 2, this is the only situation which SMJKC students did not see the withdrawal of ESL teachers as one of the interlocutors as the reason to use L1 (Mandarin). They do not really have to use L1 explain the task but they only need to rehearse the provided dialogue in L2. Thus, they conditioned this task with "pedagogical" setting where language was taken as rehearse function (Hancock, 1997 as cited in Chavez, 2003) even though all the interlocutorsinvolved were their peers.

The language use pattern when working as a whole class during ESL lessons

We have seen in the first 3 language use patterns, whenever students speak with their ESL teachers, most of the time they choose to use L2 (English) but when they interact with their peers, they prefer to use L1. So, in finding 4 as students have to interact with the whole class together with the teacher, we can see that they consistently choose to use L2 (English).The "pedagogical" setting of the interaction might be the main reason why such preference revealed. Next, perhaps the speaker and speaker grouping pattern can also explain this situation. According to Polio \& Duff, it is about "interactive effect" for the speaker role (1994, as cited in Chavez, 2003). For example, when a teacher speaks English, then the students respond in English as well, this condition will establish throughout the task. So, maybe this is what happens in a whole class interaction as Darmi et al. (2018) reported that 'English only' attitude which was emphasised in the ESL classroom in 1990's is still a shared belief among the ESL teachers in Malaysia.

Limitations

This is just a mini research that used a small part of Chavez's (2003) research on diglossia among Years 1, 2 and 3 German language students in a college. Thus, the findingsare not 
comprehensive. Besides, the sampling technique used is purposive sampling and thedata collection is in a form of nominal data which can only qualify for descriptive interpretation through frequency and percentage calculation. It is recommended to use mixed method research to get better understanding of the situation. The method that Chavez used by getting cross-sectional data between what both students and teachers desired and actually did in a language classroom could be replicated as the quantitative phase, then, followed by focus group interviews for the qualitative phase. Above all, the purposive sampling makes it hard to generalise the results to every school in Malaysia as factors like years spent in learning the language and academic performance might influence students' language preferences. In other words, the results might be different if for example, the respondents were primary school students in rural areas.

\section{Implication \& Conclusion}

From the results and discussion, we can conclude that the students' language preference changes depending on whom they are interacting with and how they perceive thesettings of the interaction. It is obvious that all students choose to use English when they need to interact with the ESL teachers. However, they will switch to L1 if the interaction takesplace outside classroom. Students also prefer to use their common shared language (in this case, their mother tongue) when interacting with their peers, even during formal classes. Theyperceived such a situation as "social" setting. Whenever the teacher is one of the interlocutorsduring ESL classes, the students use English, even when speaking to their classmates. The preference for using L1 with peers also remains consistent outside of the classroom. This could lead to the same conclusion as the research by Wahid and Pilus's (2017), which the English major students only get the chance to practise using English when they are in their classes even though they are in English-medium university. Once out of class, all local students, including those in the same English programme, use L1 (Malay).

All of this pattern here proves that our ESL classroom is diglossic, with students usingboth languages at different levels/situations of interaction. This situation is expected since bothSMK and SMJKC schools have at least bilingual students. As mentioned earlier, we did not intend to suggest alteration to the situation, rather we just wanted to identify the language use patterns in ESL classrooms with different L1 (i.e. SMK and SMJKC). However, if there is one major finding that is outstanding and noteworthy is that our students are somehow conditioned to the situation of only using English when it has to do with the "pedagogical" setting and ESL teachers. Aside from these, they tend to use L1 even when participating in ESL lesson. If this situation persists, students do not have much opportunity to practise $L 2$, which weakens their L2 acquisition. Teachers play the lead role as they need to make sure that the students absorb and practice $L 2$ to the maximum when they are in ESL classroom. Therefore, ESL teachers may use this study as reference to understand students' preference of using L1 and L2 so that they could identify where and when students utilize $L 2$ to bring in the best in L2 learning process.

\section{References}

Arumugam, N., Kaur, K., Supramanian, K., \& Thayalan, X. (2017). Code Switching in ESL Speaking Class: How \& Why? Journal of Institutional Research South East Asia, 9(2),121132. 
Creswell, J. W. (2012). Educational research planning, conducting and evaluatingquantitative and qualitative research. New York City: Pearson.

Carless, D. (2008). Student Use of the Mother Tongue in the Task-based Classroom. ELT Journal. Vol. 62(4), 331-338.

Carstens, S. A. (2018). Multilingual Chinese Malaysians: The global dimensions of language choice. Grazer Linguistische Studien, 89(November), 7-34. https://doi.org/10.25364/04.45

Chavez, M. (2003). The Diglossic Foreign-Language Classroom: Learners' Views on L1 andL2 Functions.

Darmi, R., Puteh-Behak, F., Abdulllah, H., Darmi, R., \& Wahi, W. (2018). Variations of L1 use in the English Language Class. GEMA Online ${ }^{\circledR}$ Journal of Language Studies, 18(2).

Jumal, N. A. B., AlSaqqaf, A., \& Mohamed, N. Z. N. (2019). Code Switching in Malaysian Secondary ESL Classroom: A Preliminary Study from Sabah. International Journal of Asian Social Science, 9(5), 327-334. https://doi.org/10.18488/journal.1.2019.95.327.334

Krish, P., \& May, O. C. (2020). A case study of L1 interference in speech acts amongChinese L2 students. 3 L: Language, Linguistics, Literature, 26(1), 106-118. https://doi.org/10.17576/3L-2020-2601-08

Menn, L., \& Dronkers, N. F. (2016). Psycholinguistics: Introduction and applications. Plural Publishing.

Muller, N., \& Ball, M. J. (2005). Code-switching and diglossia. Language In Society-Oxford,36, 49.

Sert, O. (2005). The functions of code-switching in ELT classroom. The Internet TESLJournal, 11(8): 1-6.

Vollmann, R., \& Soon, T. W. (2018). Chinese identities in multilingual Malaysia. Grazer Linguistische Studien, 89, 35-61.

Wahid, R., \& Pilus, Z. (2017). Learning English in a Third Space? Malay Students in anEnglishSpeaking University in Malaysia. Pertanika Journal of Social Sciences \& Humanities, 25(3), 1167-1180.

Wen, O. S., \& Chibundu, I. S. (2018). Debating vernacular school system in Malaysia: A comparative analysis of multilingual local newspapers. Search-Journal of The Southeast Asia Research Centre For Communications And Humanities, 10(2), 87-114.

Yusof, N. M. (2012). Study of social interaction among students of Vision Schools in Malaysia. Asian Ethnicity, 13(1), 47-73. https://doi.org/10.1080/14631369.2012.625697

Yussof, N. T., \& Sun, H. (2020). Mismatches between teacher beliefs, practices and reasonsfor English use in preschool Malay language classrooms. Language and Education, 34(4), 363-382. https://doi.org/10.1080/09500782.2020.1720230 